PROCEEDINGS OF THE WORLD CONFERENCE ON OZONE THERAPY IN MEDICINE, DENTISTRY AND VETERINARY. ANCONA (ITALY). SEPTEMBER 22nd - 23rd - 24th, 2017

\title{
Ozone therapy can be considered as an integrative therapy in oncology? [abstract]
}

\author{
Paolo Tordiglione, Fabio Silvio-Mario Araimo, Carmela Imperiale, S. Zancla
}

Policlinic Umberto I, University Hospital of Sapienza, Rome, Italy.

\section{ABSTRACT}

\section{OPEN ACCESS}

\section{Citation \\ Tordiglione P, Araimo FS, Imperiale C, Zancla S. Ozone therapy can be considered as an integrative therapy in oncology? [abstract]. Proceedings of The World Conference on Ozone Therapy in Medicine, Dentistry and Veterinary. Ancona (Italy). September 22nd - 23rd - 24th , 2017. J Ozone Ther. 2019;3(4):74-75. doi: 10.7203/ jo3t.3.4.2019.15547}

Academic Editor Jose Baeza-Noci,

School of Medicine, Valencia University, SPAIN

\section{Editor}

World Federation of Ozone Therapy, Bolgna, ITALY

\section{Received}

June 17, 2019

\section{Accepted}

December 08, 2019

Published

December 30, 2019

\section{Intellectual Property}

Paolo Tordiglione.

This is an open access article distributed under the terms of the Creative Commons Attribution License (CC BY 4.0), which permits unrestricted use, distribution, and reproduction in any medium, provided the original author and source are credited.

\section{Author Information}

tordiglione@rocketmail.com
Background. Our group in Policlinic Umberto I - University Hospital of Sapienza Rome - has decided to further investigate if Ozone therapy can be of support in oncology.

In literature it has been reported that ozone applications in oncology or in cancer cells is associated with: high efficiency in preventing chemotherapy complications (nausea, vomiting, opportunistic infections, asthenia) as well as confining or restricting the expansion of tumours [1-5].

Purpose. The aim of our study in to evaluate and eventually confirm the validity of ozone treatments in order to consider such procedures as a possible and concrete support therapy for oncology patients undertaking chemotherapy. A statistical significance and clinical evaluation of our work would finally give a scientifically validation, still missing, to officially consider ozone therapy as one of the many possible integrative therapy in oncology.

Design. It is a pilot study designed and approved by the Ethical Committee of the University of Rome, La Sapienza (March 2017) to evaluate quality of life and reduction of side effects of adjuvant chemotherapy in 20 breast cancer patients.

Methods. The selected patients will be treated with systemic ozone treatment: Ozonated autohemotherapy will be performed according to the following method: $200 \mathrm{ml}$ venous blood will be exposed an equal amount of O2 /O3 $(200 \mathrm{ml})$ The ozone concentration will be gradually increased as follows: $20-30-40 \mathrm{mcrg} / \mathrm{mL}$ with a specific schedule until each patient will receive 15 applications overall. The sessions will be scheduled according to a specific timetable during the administration of adjuvant chemotherapy by means of Epirubicin and Cyclophsphamide (EC) every 3 weeks for 4 cycles followed by Paclitaxel for 12 consecutive weeks.

Ozone therapy will not be applied on days of chemotherapy in order to avoid interaction between chemotherapeutics and ozonides. Biochemical blood analysis and stress oxidative blood test will be used as parameters for activity of antioxidant defence system. Quality of life will be evaluated with Fact G Test.

It is the first study to have been evaluated and approved by an official university ethical committee and we will be glad to publish our result as soon as possible. On this behalf it would be great if any other centre could be interested in cooperating with us so to transform this pilot study into a multicentre study with larger numbers and therefore, with a greater impact on the international community. 
Our aim is to give cancer patients a better life quality in general and especially help them overcome all the side effects during the chemotherapy. This could open a new scenario in the alternative complementary treatments in oncology.

\section{References}

1. Luongo M, Brigida AL, Mascolo L, Gaudino G. Possible Therapeutic Effects of Ozone Mixture on Hypoxia in Tumor Development. Anticancer Res. 2017;37(2):425-435. doi:10.21873/anticanres.11334.

2. Delgado-Roche L, Hernández-Matos Y, Medina EA, Morejón DÁ, González MR, Martínez-Sánchez G. Ozone-Oxidative Preconditioning Prevents Doxorubicin-induced Cardiotoxicity in Sprague-Dawley RatsSultan Qaboos. Sultan Qaboos Univ Med J. 2014;14(3):e342-348

3. Zanardi I, Borrelli E, Valacchi G, Travagli V, Bocci V. Ozone: A Multifaceted Molecule with Unexpected Therapeutic Activity. Curr Med Chem. 2016;23(4):304-14. doi:10.2174/0929867323666151221150420.

4. Clavo B, et al. Ozone Therapy for Tumor Oxygenation: a Pilot Study. Evid Based Complement Alternat Med. 2004 Jun 1;1(1):93-98. doi:10.1093/ ecam/neh009.

5. Bocci V, Larini A, Micheli V. Restoration of Normoxia by Ozone Therapy May Control Neoplastic Growth: A Review and a Working Hypothesis. J Altern Complement Med. 2005 Apr;11(2):257-265. doi:10.1089/ acm.2005.11.257. 